\title{
X-ray Fluorescence Analysis of Iron Ores Using Graphite Powder as an Inert Binder*
}

\author{
By Kimitaka SATO** and Yoshio UZUKI**
}

\begin{abstract}
Synopsis
With a view to improving the rapidity and precision of $X$-ray fluorescence analysis of briquetted iron ores, a comparison was made of the natures of surfaces of briquetted samples prepared by a newly proposed dry grinding method using graphite powder as a binder and by three conventional methods, viz. a dry grinding method using no binder, a wet grinding method using stearic acid powder and a wet grinding method using polystyrene-maleic acid powder as a binder. An electron probe microanalyzer and a scanning electron microscope were used in this investigation. The results obtaind are as follows:

(1) The new graphite grinding method is more suitable for the minute grinding of iron ores than other grinding methods and can produce iron ores with a uniform particle size of $I$ / $\mathrm{m}$ under.

(2) By grinding through the graphite grinding method, iron ore powders are readily prepared into briquet after grinding, thus shortening the time necessary for briquetting.

(3) The internal standard $\left(\mathrm{Co}_{2} \mathrm{O}_{3}\right)$ is uniformly and homogeneously dispersed in the briquet prepared by the graphite grinding method, compared with other grinding ones.

(4) Calibration curves exactly became simple for the important components in iron ores, that is, total $\mathrm{Fe}, \mathrm{CaO}, \mathrm{SiO}_{2}, \mathrm{Al}_{2} \mathrm{O}_{3}$ and $\mathrm{MgO}$ by adopting the graphite grinding method.

(5) Repeatability $\dagger$ and precision $\dagger+\left(\sigma_{d}\right)$ were improved by the graphite grinding method. For example, $\sigma_{d}$ was 0.43 for total $\mathrm{Fe}$ and 0.05 for $\mathrm{CaO}$.

As mentioned above, the graphite powder has the grinding effect as a solid lubricant by the use of the graphite grinding method, so that the briquet obtained becomes uniform with improvements in repeatability and precision. The graphite grinding method is also suitable for the analysis for process control.
\end{abstract}

\section{Introduction}

Iron ores are really complicated in the mineralogical structure and the distribution of particle sizes, so there are many problems which need further clarification in the analysis of the components of iron ores. ${ }^{1)}$ Recently, instrumental analyses have extensively been adopted from the necessity of treating rapidly a lot of samples in the process control of steel works and X-ray fluorescence analysis has been applied over the wide fields of the analysis of iron and steel ${ }^{2)}$ with the progress of analytical instruments, although a wet chemical analysis is generally employed for the elemental analysis of iron ores. In the analysis of powdered samples such as iron ores, it is necessary to prepare samples previously for measurement, for that briquetting ${ }^{3,4)}$ or fusion techniques ${ }^{5-7)}$ are commonly applied. These techniques, however, have not ever been established so far.

As the components of iron ores prepared with briquetting technique are measured by the use of an $\mathrm{X}$-ray fluorescence analysis, the characteristics of grinding of iron ores are different corresponding to their mineral compositions and particle size distributions, whose influence on the analytical values are regarded as the important points in X-ray fluorescence analysis of iron ores through briquet technique. Various methods for correction have been discussed from the view point of the effects of matrix and particle size in order to solve their problems. ${ }^{8-11)}$ It has been also tried to obtain a homogeneous briquetted sample and to simplify a calibration curve. Consequently, a wet grinding-briquetting method using an internal standard ${ }^{4)}$ was developed as one of the sample preparing technique of iron ores for the X-ray fluorescence analysis. Nevertheless, it became necessary to establish more useful technique for sample preparation so as to operate rapidly, to improve a repeatability and precision and to apply a briquetting method to every band of iron ores.

In this paper, various briquetted samples prepared through some former grinding methods were compared especially for the surface characteristics. Moreover, the important problems which must be solved in the X-ray fluorescence analysis of powder were newly extracted and were discussed. The wet grinding method $^{4}$ preferably was mainly compared and discussed with the dry grinding method using graphite powder as an inert binder newly proposed. The principal reason which the graphite grinding method was devised is that graphite powder has a lubricant effect ${ }^{12,13)}$ as a grinding agent through the dry grinding process and gives no influence for the fluorescent X-ray intensities of analytical components.

As the results, the dry grinding method using graphite powder could be well confirmed to be useful sample preparing technique which improved the disadvantages of former grinding methods in the $\mathrm{X}$-ray fluorescence analysis of iron ores.

\section{Experimental}

\section{Iron Ore Specimens}

Four brands of iron ores estimated to have different characteristics of grinding were used. The iron ores were selected due to the results of the mineralogical studies of iron ores. ${ }^{14}$ ) The criterion of the selection was as follows:

* Originally published in J. Japan Inst. Metals, 36 (1972), 648, in Japanese. English version received December 19, 1973.

** Fundamental Research Laboratories, Nippon Steel Corp., Ida, Nakahara-ku, Kawasaki 211.

+ Variance of analytical values for same sample.

+ + Standard deviation of the difference between the analytical values $(X)$ and standard chemical values $(C)$ calculated from the following equation. $\quad \sigma_{d}=\sqrt{ } \sum(X-C)^{2} /(n-1) \quad(n$ : authorized number of samples) 
Table 1. Chemical and mineralogical compositions of iron ore samples $(\%)$

\begin{tabular}{l|rrrrrrrl}
\multicolumn{1}{c}{ Brands } & T. Fe & $\mathrm{CaO}$ & $\mathrm{SiO}_{2}$ & $\mathrm{Al}_{2} \mathrm{O}_{3}$ & $\mathrm{MgO}$ & $\mathrm{P}_{2} \mathrm{O}_{5}$ & $\mathrm{~S}$ & Mineral composition* \\
\hline Goa & 61.62 & 0.02 & 4.46 & 2.09 & 0.08 & 0.156 & 0.011 & hematite, goethite, gibbsite, $\alpha$-quartz, kaolinite \\
Brazil & 64.25 & 0.06 & 5.52 & 1.36 & 0.05 & 0.097 & 0.004 & hematite, $\alpha$-quartz, chlorite \\
Hamersley & 66.17 & 0.04 & 2.23 & 1.27 & 0.05 & 0.070 & 0.011 & hematite, kaolinite \\
Lamco & 45.44 & 0.24 & 35.65 & 0.16 & 0.34 & 0.081 & 0.003 & magnetite, hematite, $\alpha$-quartz, mica
\end{tabular}

* Obtained with a X-ray diffraction method

(1) Goa iron ore (India) - It consists of much limonite mineral effloresced well and tends to be easily ground.

(2) Brazil iron ore-It mainly consists of hematite.

(3) Hamersley iron ore (Australia) - It consists of much fine crystal of hematite.

(4) Lamco iron ore (Liberia) - It lies together with a lot of $\alpha$-quartz.

The chemical and mineralogical compositions of the specimens are summarized in Table 1 .

Furthermore, the standard specimens of iron ores of about 30 kinds involving NSC (our corporation) standards, National Bureau of Standards (NBS), Bureau of Analysed Samples (BCS) and Japanese Standards of Iron and Steel (JSS) as shown in Table 2 were also used in order to draw up the calibration curves and to authorize repeatabilities and precisions.

\section{Sample Preparing Procedure}

The following four grinding methods were compared in this investigation.

(1) Dry grinding method using no binder. We call it " no binder grinding method" for short.

(2) Wet grinding method in the solvent of $n$ hexane using the powder of stearic acid as an inert binder. We call it "SA grinding method" for short.

(3) Wet grinding method in the solvent of $n$ hexane using the powder of polystyrene-maleic acid copolymer as an inert binder. We call it "PSM grinding method " for short.

(4) Dry grinding method using graphite powder as a grinding agent and an inert binder. We propose the method as a new technique and call it "graphite grinding method" for short.

Graphite powder employed was high purity grade "SP-1" manufactured by Nippon Carbon Co., Ltd. $\mathrm{Co}_{2} \mathrm{O}_{3}$ was also added into the analytical samples as an internal standard, since it was effective in the $\mathrm{X}$-ray fluorescence analysis of heterogeneous powdered specimens. ${ }^{4)}$

At the operation of grinding, iron ores, $\mathrm{Co}_{2} \mathrm{O}_{3}$ and each binder were ground after mixing in the order as shown in Fig. 1. The mixing ratio, especially of graphite powder for "graphite grinding method," was determined according to the following view. That is, the graphite powder corresponding to about $5 \%$ for all the ground matters was added in this experiment, because the ground matter did not adhere to the inner wall of grinding vessel and could be easily taken out of it when the mixing ratio of graphite powder is 3 to $20 \%$ for the total amounts of ground
Table 2. Standard values of iron ore specimens (\%)

\begin{tabular}{|c|c|c|c|c|c|}
\hline No. & T. $\mathrm{Fe}$ & $\mathrm{CaO}$ & $\mathrm{SiO}_{2}$ & $\mathrm{Al}_{2} \mathrm{O}_{3}$ & $\mathrm{MgO}$ \\
\hline 1 & 59.73 & 4.10 & 7.37 & 1.70 & 0.68 \\
\hline 2 & 66.54 & 0.03 & 1.27 & 1.64 & 0.05 \\
\hline 3 & 58.70 & 0.56 & 10.75 & 1.70 & 0.82 \\
\hline 4 & 62.88 & 0.04 & 6.69 & 1.79 & 0.08 \\
\hline 5 & 56.08 & 0.16 & 13.77 & 2.57 & 0.18 \\
\hline 6 & 55.73 & 7.41 & 9.90 & 1.87 & 1.00 \\
\hline 7 & 64.34 & 2.26 & 5.26 & 0.93 & 0.32 \\
\hline 8 & 62.40 & 0.90 & 4.53 & 0.54 & 4.63 \\
\hline 9 & 65.78 & - & 1.92 & 1.66 & - \\
\hline 10 & 64.68 & 0.05 & 1.84 & 1.54 & 0.09 \\
\hline 11 & 56.09 & 0.05 & 17.74 & 0.87 & 0.08 \\
\hline 12 & 65.20 & 0.02 & 3.63 & 0.99 & - \\
\hline 13 & 62.01 & 1.72 & 5.51 & 1.20 & 1.08 \\
\hline 14 & 59.15 & 1.04 & 6.74 & 0.86 & 1.57 \\
\hline 15 & 64.31 & 0.02 & 5.40 & 1.40 & 0.03 \\
\hline 16 & 65.30 & 0.04 & 3.78 & 1.11 & 0.02 \\
\hline 17 & 51.75 & 4.04 & 12.21 & 1.00 & 8.24 \\
\hline 18 & 60.58 & 1.69 & 6.98 & 1.29 & 1.20 \\
\hline 19 & 63.17 & 0.84 & 5.63 & 1.34 & 1.27 \\
\hline 20 & 59.64 & 0.05 & 1.31 & 4.70 & 0.05 \\
\hline 800 & 62.92 & 0.05 & 2.61 & 2.01 & 0.25 \\
\hline 801 & 64.63 & 0.06 & 2.13 & 2.57 & 0.05 \\
\hline 830 & 60.54 & 0.70 & 2.27 & 2.86 & 2.17 \\
\hline 850 & 66.83 & 0.39 & 2.56 & 0.55 & 0.77 \\
\hline 600 & 61.91 & 0.16 & 3.18 & 3.28 & 0.18 \\
\hline 601 & 56.62 & 1.33 & 9.43 & 2.69 & 1.53 \\
\hline 602 & 60.54 & 0.07 & 1.73 & 4.79 & 0.10 \\
\hline 603 & 64.94 & 2.09 & 3.77 & 0.96 & 1.12 \\
\hline 605 & 60.20 & 0.16 & 4.08 & 3.85 & 0.92 \\
\hline 606 & 56.98 & 0.07 & 2.67 & 6.74 & 0.09 \\
\hline 27 & 65.00 & 0.06 & 2.08 & - & - \\
\hline 175 & 66.15 & 0.28 & 3.52 & 1.10 & 1.49 \\
\hline
\end{tabular}

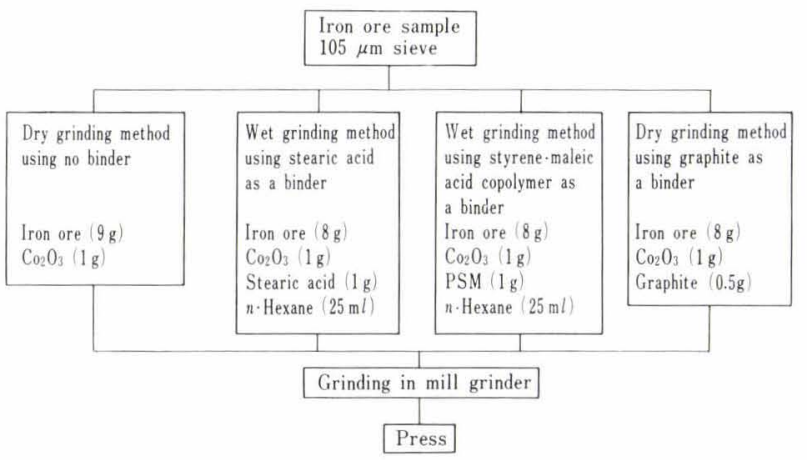

Fig. 1. Grinding methods compared in this paper 
matter. Still more, the matter adhered to the inner wall of grinding vessel when the mixing ratio of graphite powder added was less than $3 \%$, while considerable time was necessary to grind the matters when the ratio was more than $20 \%$.

The mixing samples were put into the grinding vessel of stainless steel and were ground by using a disk typed vibrating mill for $10 \mathrm{~min}$. After grinding the powder was pressed to prepare a briquet, by using a aluminium ring if necessary.

The effect of fluorescent X-ray intensity was also investigated in the rage of minute sizes of particle under $30 \mu \mathrm{m}$ by using a Sweden iron ore purified by magnetic separation (involving 99\% of magnetite) which was passed through the sieves of $105 \mu \mathrm{m}$ was separated into each size of particle with a new ultrasonic vibration sieve technique developed in our laboratory. ${ }^{15}$ ) The samples were dried over after washing them in an alcohol solution containing $5 \%$ of ethyl cellulose for $1 \mathrm{~g}$ of each fraction of particle size and then, the minibriquets of $13 \mathrm{~mm}$ in diameter were prepared at the pressure of $2 \mathrm{t} / \mathrm{cm}^{2}$ and $12 \mathrm{t} / \mathrm{cm}^{2}$.

\section{Experimental Procedure and Condition}

For each briquet prepared, an X-ray fluorescence analysis was taken out and the dispersing state of internal standered $\left(\mathrm{Co}_{2} \mathrm{O}_{3}\right)$ in the briquet was observed with the characteristic X-ray images by an electron probe microanalyzer. The uniformity of particle size, the distribution of size less than $2 \mu \mathrm{m}$ and the characteristics of surface were also studied from the observation by optical and scanning electron microscopes.

$\mathrm{X}$-ray fluorescence analysis was carried out with a Norelco $100 \mathrm{kV}$ constant potential spectrograph and a Rigaku model KG-X spectrometer on the basis of the operating conditions as shown in Table 3. X-ray microanalysis was taken out with a Shimadzu-ARL model EMX-SM electron probe microanalyzer and SEM observation with a JEOL model JSM-U3 scanning electron microscope.

\section{Experimental Results}

\section{Features of Grinding}

The appearances of the grindings were compared among the four kinds of grinding methods involving "graphite grinding method." The results obtained are described as follows. By using with the "no binder grinding method ", minute matters condensed and adhered to the inner wall of a grinding vessel with the elapse of a few minute. After $10 \mathrm{~min}$, the matters could not be easily taken out of the wall because of adhering strongly. The tendency was severely observed, especially in the case of iron ores involving a lot of limonite minerals. By using the " no binder grinding method", it was observed with an optical microscope that the 60 to $80 \%$ of iron ores were ground to the particle size of less than $2 \mu \mathrm{m}$, while the particle size was distributed over a wide range since rough particles were also obtained together. With the "SA grinding method", iron ores
Table 3. Operating conditions

\begin{tabular}{lccclll}
$\begin{array}{l}\text { Sepectral } \\
\text { line }\end{array}$ & Target $\begin{array}{c}\text { Voltage Current } \\
(\mathrm{kV})\end{array}$ & $\begin{array}{c}\text { Crystal } \\
(\mathrm{mA})\end{array}$ & Detector & $\begin{array}{c}\text { Itegra- } \\
\text { tion time } \\
(\mathrm{sec})\end{array}$ \\
\hline FeK $\beta^{*}$ & $\mathrm{~W}$ & 30 & 20 & $\mathrm{LiF}$ & S.C. & 30 \\
Fek $\beta$ & $\mathrm{Gr}$ & 40 & 10 & LiF & S.C. & 20 \\
$\operatorname{CoK} \alpha *$ & $\mathrm{~W}$ & 30 & 20 & LiF & S.C. & 30 \\
$\operatorname{CoK} \alpha$ & $\mathrm{Cr}$ & 40 & 10 & LiF & S.C. & 20 \\
$\operatorname{CaK} \alpha$ & $\mathrm{Cr}$ & 50 & 40 & LiF & S.C. & 20 \\
$\operatorname{SiK} \alpha$ & $\mathrm{Cr}$ & 50 & 40 & EDDT & F.P.C. & 20 \\
$\operatorname{AlK} \alpha$ & $\mathrm{Cr}$ & 50 & 40 & EDDT & F.P.C. & 40 \\
$\operatorname{MgK} \alpha$ & $\mathrm{Cr}$ & 50 & 40 & ADP & F.P.C. & 40
\end{tabular}

* These conditions were used with a Norelco type spectrometer, and the others with a Rigaku type spectrometer.
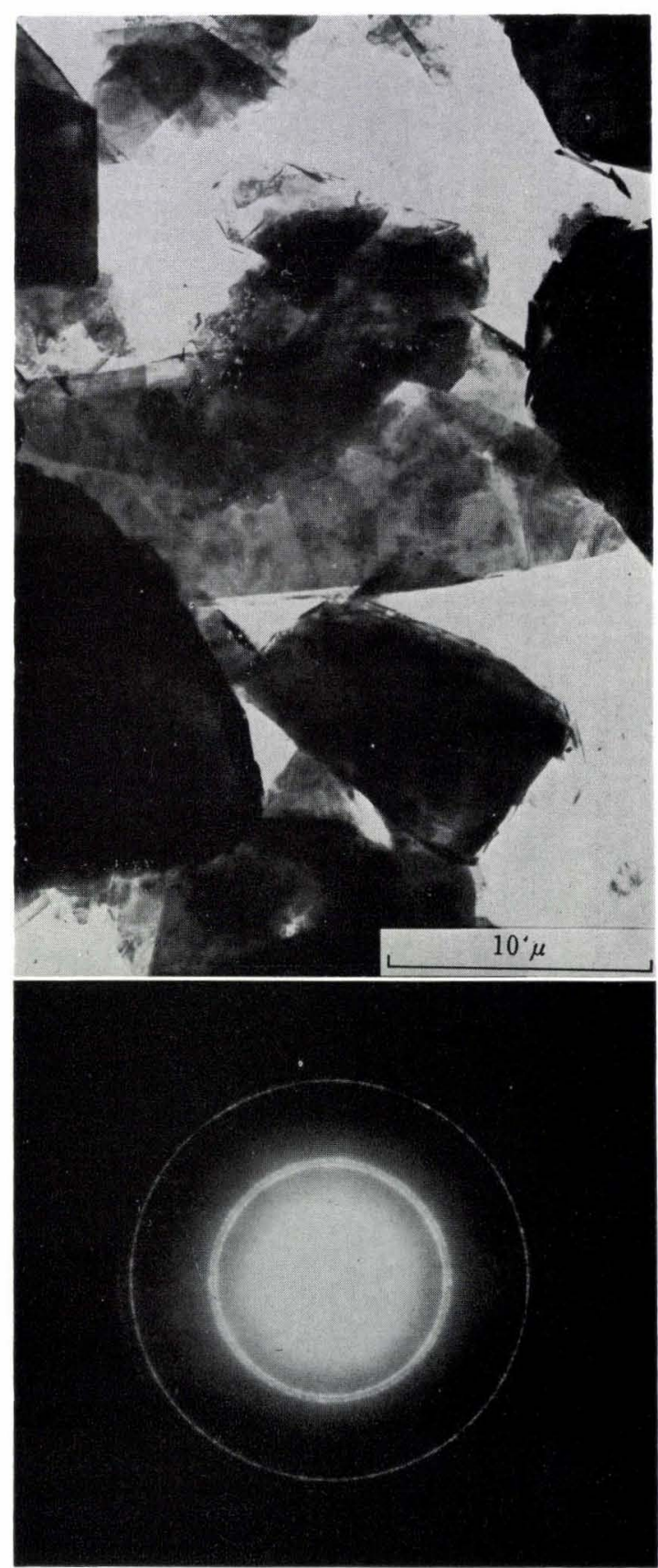

Photo. 1. Electron Micrograph and diffraction pattern of graphite powder used in this experiment (Nippon Carbon; $\mathrm{SP}-1$ ) 
were rather ground, but the ground particles were liable to condense. Further, highly rustling powders were obtained with an uniform size of particle after removing $n$-hexane, by the use of the " PSM grinding method". The grinding method is suited for obtaining a minute particle in comparison with the "SA grinding method". Both the wet grinding methods, however, are necessary to some extent of time to remove $n$-hexane as solvent.

The ground matters did not adhere to the inner wall of grinding vessel and became to a highly rustling powder through the "graphite grinding method", in which the post-treatment was quite easy because of dry grinding, as compared with the above three grinding methods. The graphite powder used is the crystal of plate form and cleaves easily as shown in Photo. 1, so it has a little frictional force and a lubricant effect. ${ }^{12)}$ Consequently, it is estimated that the nature of graphite powder must probably play an important role in the process of grinding.

\section{Surface Characteristics of Briquets}

The flatness of surface, the size and the mixing state of particles were examined for the briquet obtained through the prescribed grinding procedures with the observation by a scanning electron microscope. The results obtained in this approach are well illustrated in Photos. 2 to 3.

The secondary electron images are first compared for the briquets obtained by the Brazil iron ore as illustrated in Photo. 2. The image was indistinct in the case of the " no binder grinding method ", while the states of surface were clearly observed in the case of the other three grinding methods. From the results of the examination, it was recognized that, by the use of the " no binder grinding method", very fine particles segregated to the surface of briquet, most of which levelled off, while larger particle still remained partially without being ground. The "graphite grinding method " was a useful technique to get a briquet of flat surface in comparison with the other two grinding methods except the "no binder grinding method". The tendency is estimated especially on the basis of the nature of binders. The similar tendency was also observed in the case of the briquet made from the Lamco iron ore involving a lot of $\alpha$-quartz the grinding of which was especially difficult, as illustrated in Photo. 3. From the results, it seems most reasonable to conclude that the "graphite grinding method" is a useful technique which can be finely ground and mixed, even if an iron ore contains the minerals which are difficult to be ground.

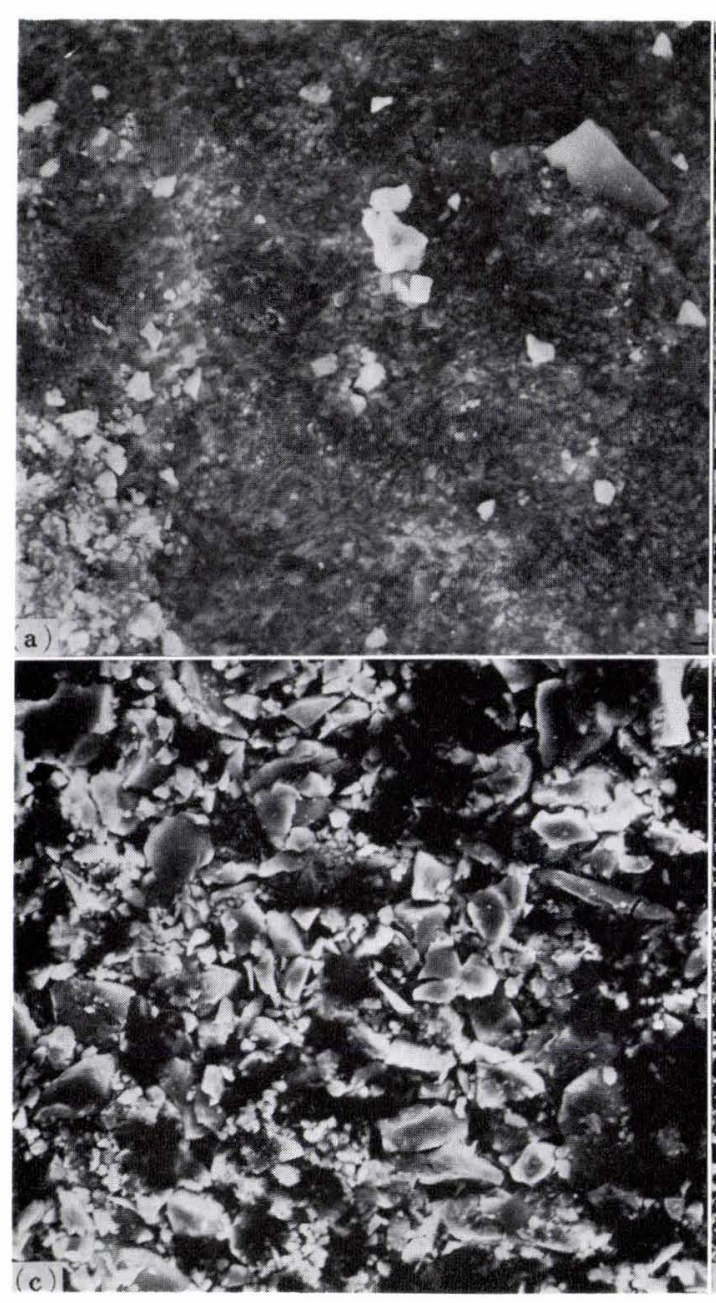

(a) Dry method using no binder

(c) Wet method using PSM powder

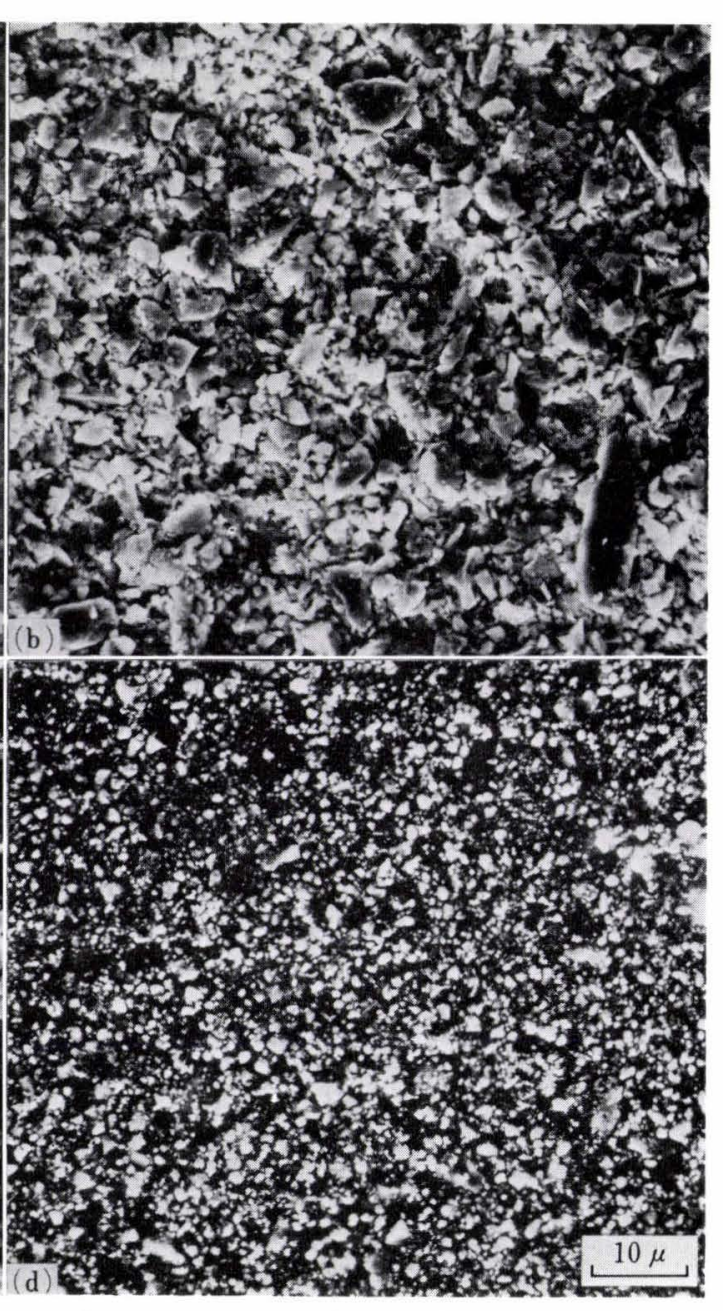

(b) Wet method using stearic acid

(d) New dry method using graphite

Photo. 2. Secondary electron images of the surface of briquet of Brazil ore prepared by various sampling method 


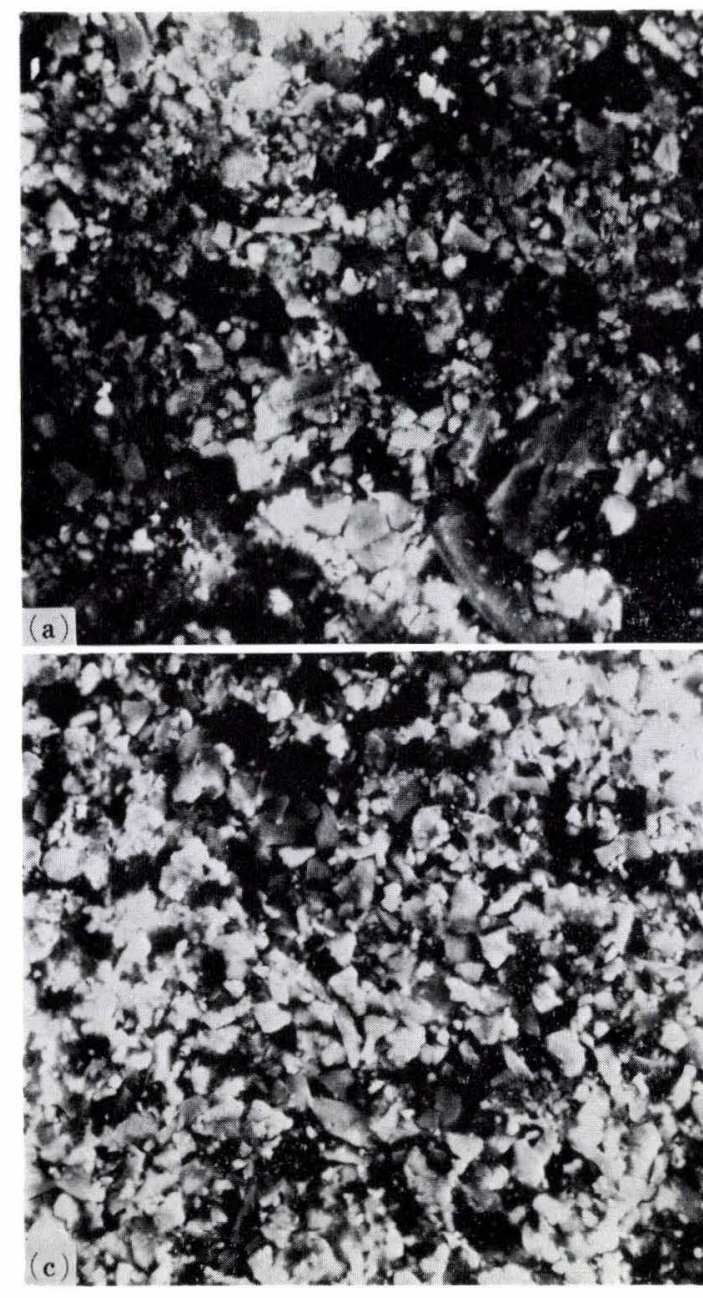

(a) Dry Method using no binder

(c) Wet method using PSM powder
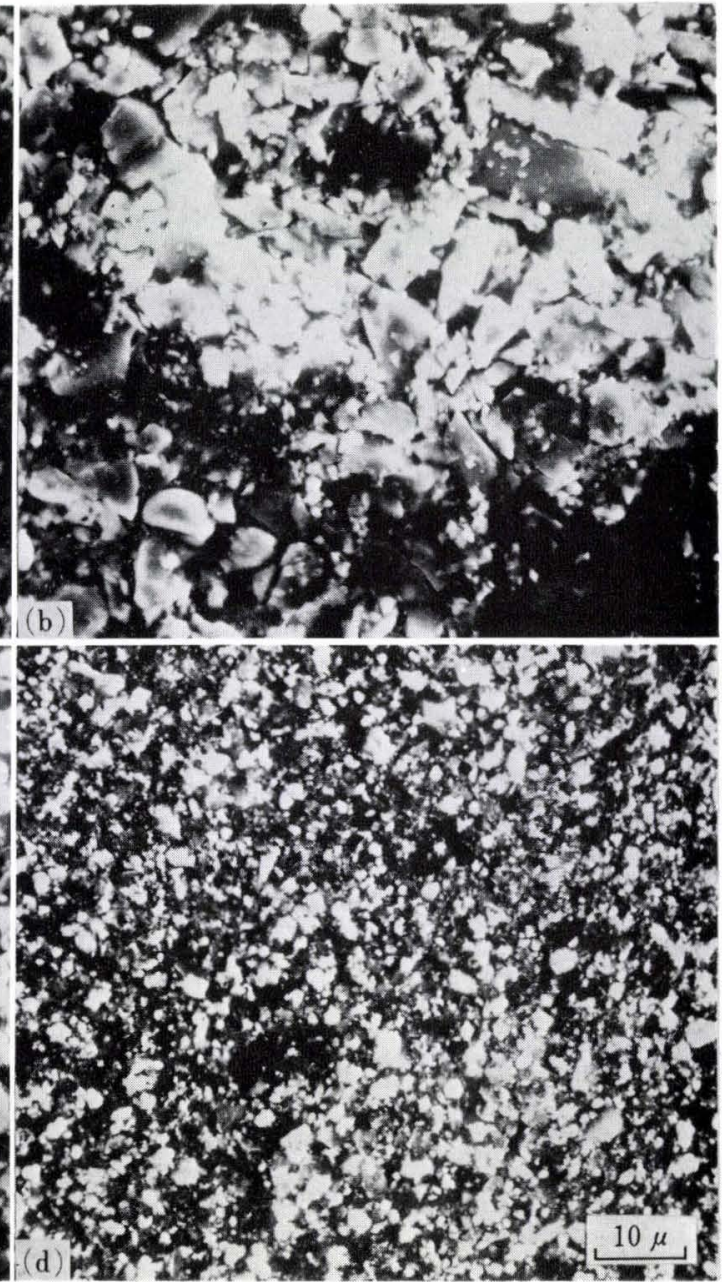

(b) Wet method using stearic acid

(d) New dry method using graphite

Photo. 3. Secondary electron images of the surface of briquet of Lamco ore prepared by various sampling method

The following results were also recognized with regard to the sizes of particle. The particles are uniformly dispersed in the briquets obtained through the three grinding methods except the " no binder grinding method". The particle size was distributed within the range of less than $5 \mu \mathrm{m}$ in the two wet grinding methods, while the briquets obtained is mostly composed of the particle sizes of about $1 \mu \mathrm{m}$ in the case of the "graphite grinding method".

As the above-mentioned results, it may be concluded that the "graphite grinding method" is the best sample preparing procedure among the four grinding methods compared from the viewpoints of the composition of minute particles and the uniform distribution of ground particles on the surface of briquets.

\section{Dispersing State of Internal Standard Material}

In a X-ray fluorescence analysis using briquet, it is necessary for an internal standard material to disperse uniformly in the briquet. In order to examine the problem, an internal standard material was added into ground matters before grinding in this investigation. In this section, we will mainly state the results obtained on the distribution of the material by the use of an electron probe microanalyzer, by noting to the dispersed state of $\mathrm{Co}_{2} \mathrm{O}_{3}$ and main elements in the briquet.

Photographs 4 and 5 are the examples of the results obtained in this investigation. As shown in Photo. 4, it was found that iron, cobalt and silicon dispersed uniformly in the briquets obtained through the dry grinding methods rather than in the briquets through the wet grinding methods, in comparison with the characteristic X-ray images of the elements for the briquet obtained from the Brazil iron ore.

Furthermore, similar examination was also carried out for the Lamco iron ore (involving $\alpha-\mathrm{SiO}_{2}$ of $35.65 \%$ which is especially difficult to grind), in order to see the tendency on an iron ore made up of peculiar minerals. As shown in Photo. 5, the influence of mineral composition on the surface characteristics of briquet could not be especially recognized and the tendency was nearly similar to the case of the Brazil iron ore. As mentioned above, no matter how different the brand of iron ores might be, the tendency is similar among the four grinding methods tried in this investigation. From the viewpoint of the dispersed state of particles in the briquets, however, the "graphite grinding method" can be generally judged to be best technique in comparison with the other three 

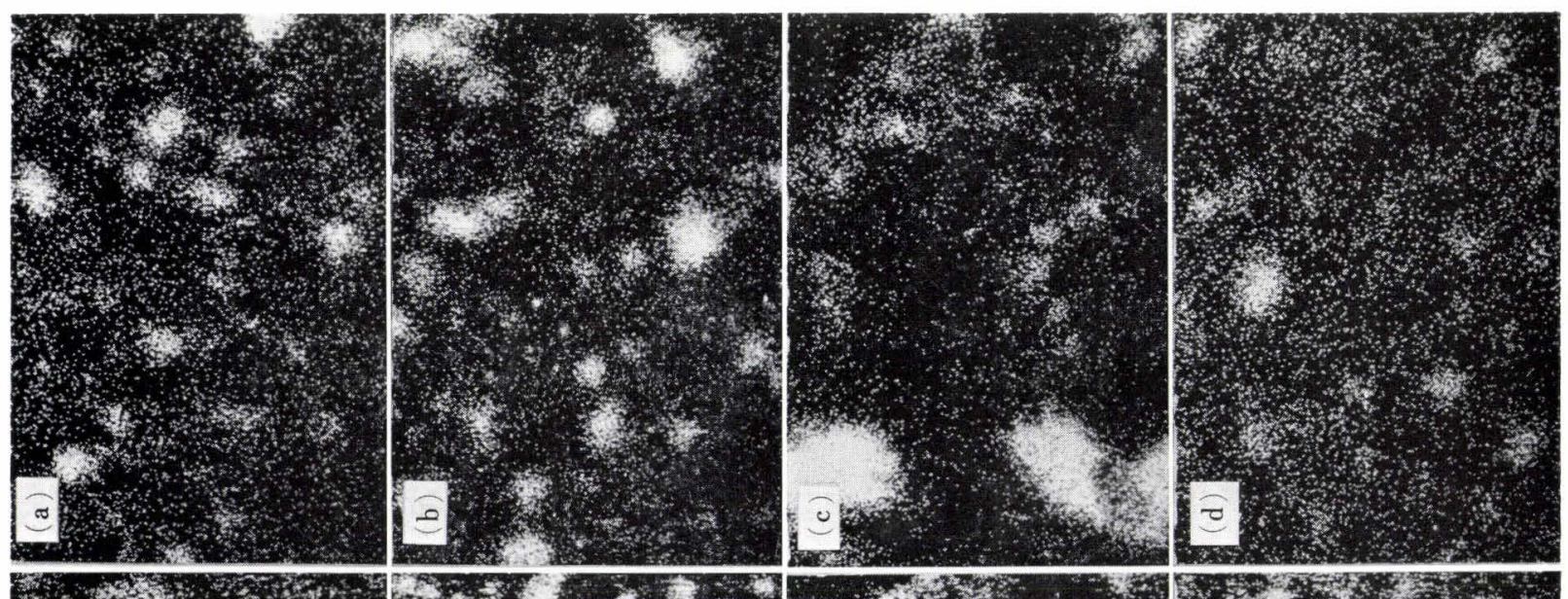

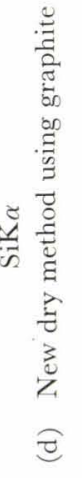
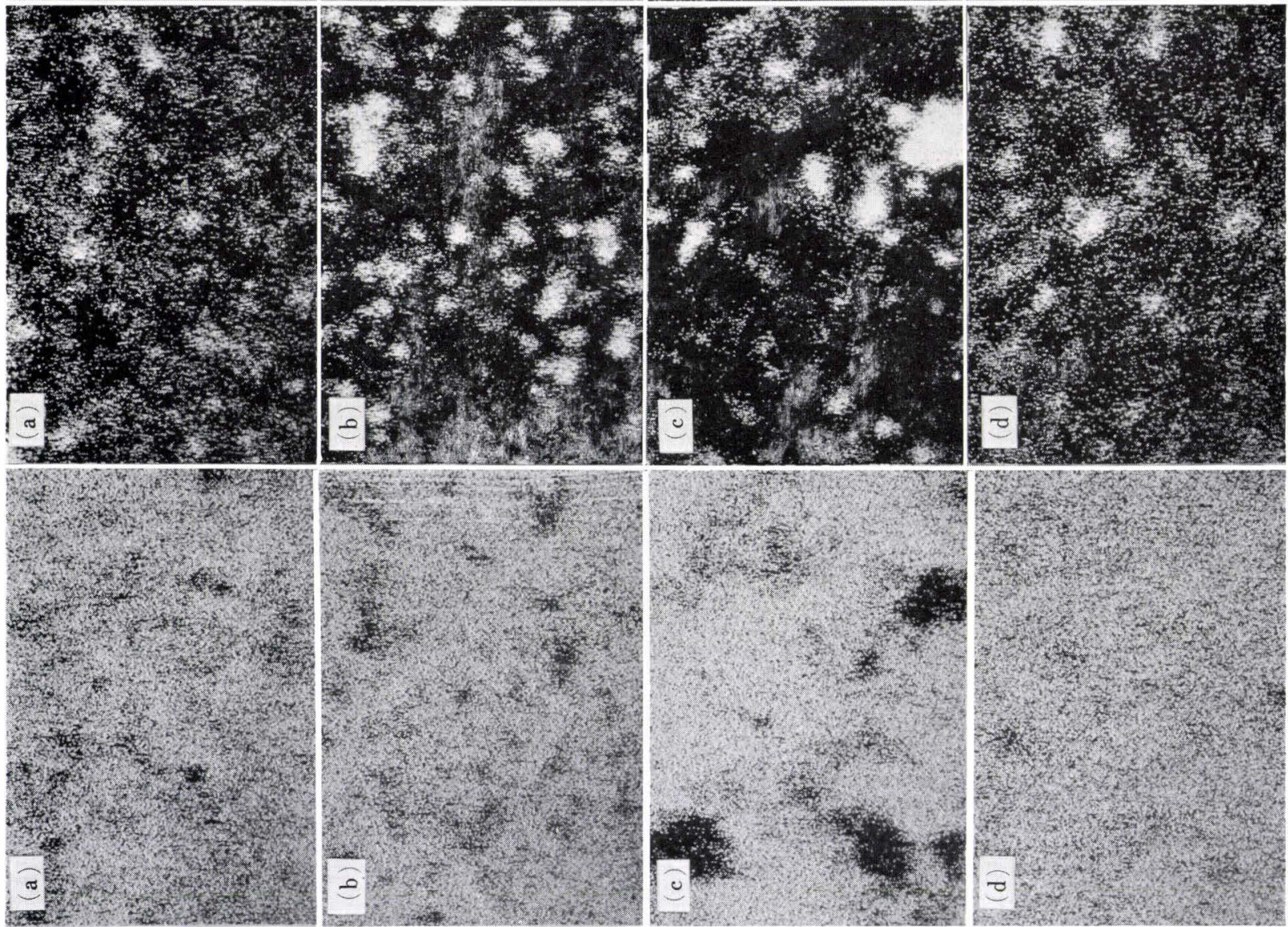

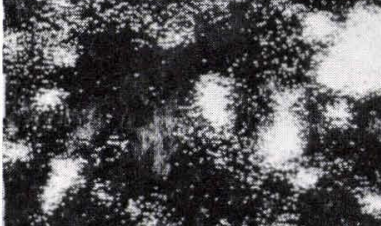

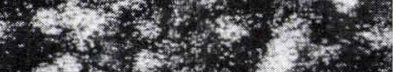
b. 30 $0 .+2$
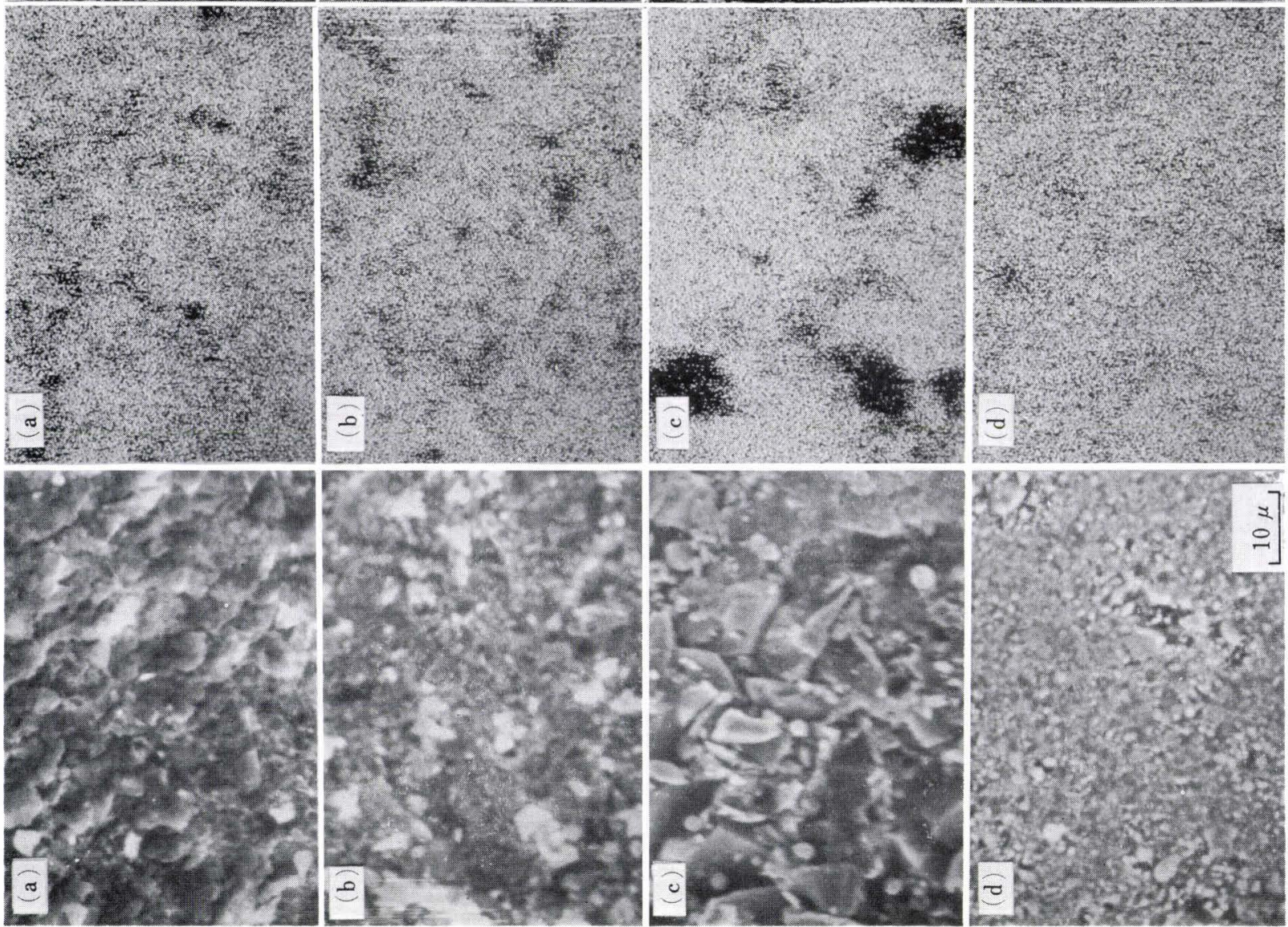

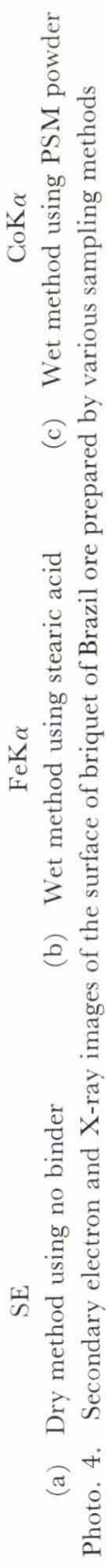



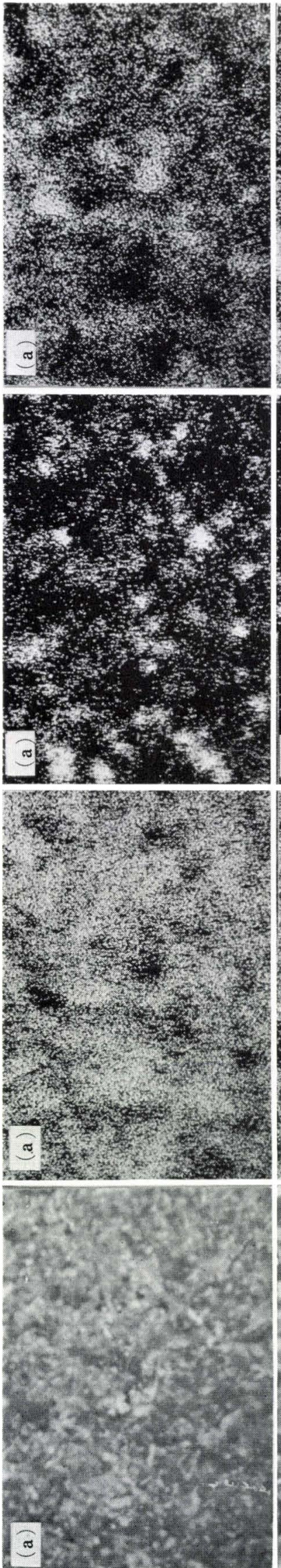
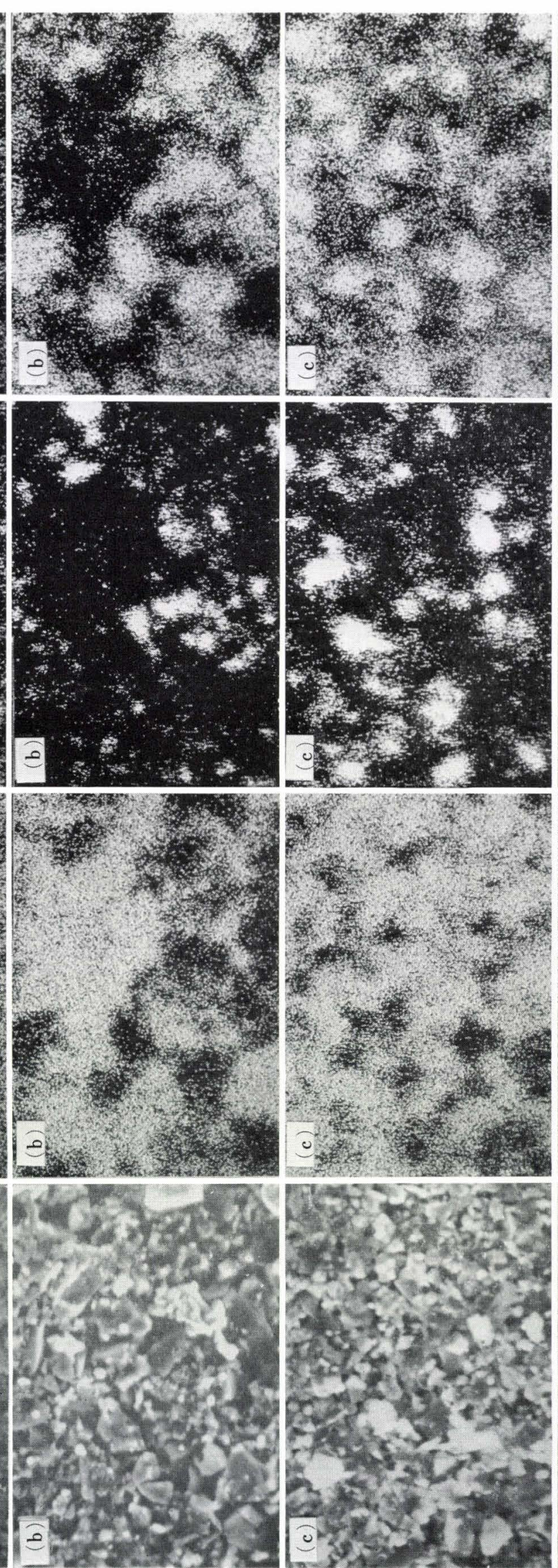

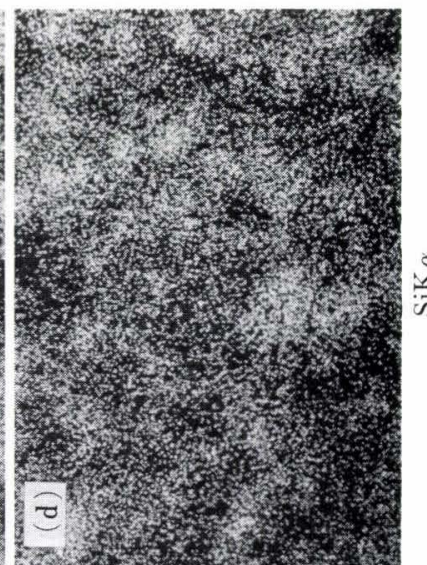

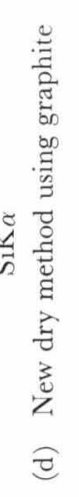

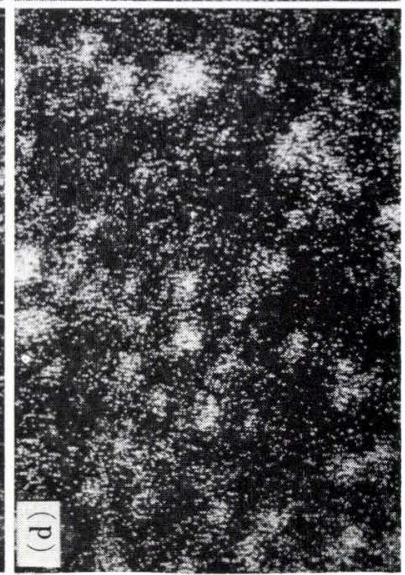

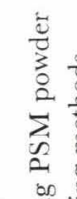

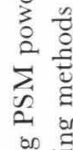

零

s

苞.

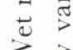

$\geq 3$

()

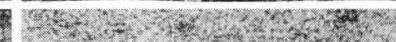

$x^{2}+x^{2}=0$$$
4
$$$$
\text { 륨 }
$$

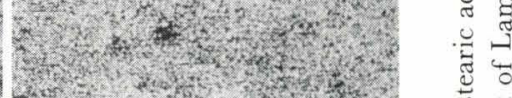

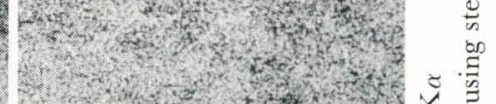

马.

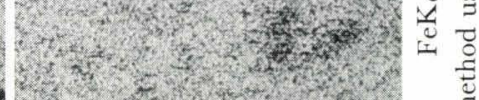

䡈

范

3

है

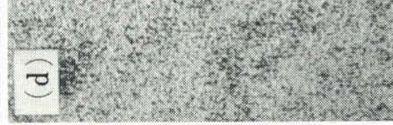

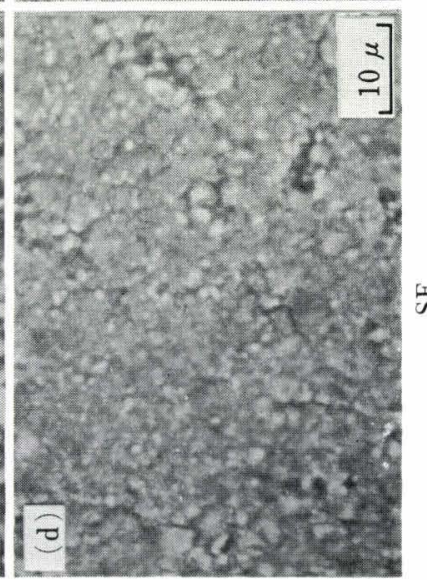

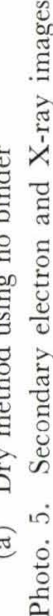


grinding methods.

In addition, it is attractive that the new information can be obtained for the surface characteristics of briquet by the use of an electron probe microanalyzer. The technique may be widely applied to the field dealt with powder.

\section{Calibration Curve, Repeatability and Precision}

From the previously described viewpoints, it was understood that the "graphite grinding method" might be an excellent sample preparation technique. Consequently, the investigation described below was taken out mainly by the "graphite grinding method" and the calibration curves were first drawn up by using the briquets obtained through the grinding method. The calibration curves were correlated to the standard values with the ratio between the fluorescent X-ray intensities of intended and reference brands for the main components, that is, Total Fe, $\mathrm{CaO}$, $\mathrm{SiO}_{2}, \mathrm{Al}_{2} \mathrm{O}_{3}$ and $\mathrm{MgO}$ in iron ore. The results obtained are illustrated in Figs. 2 to 6.

The calibration curves are linear in the wide range of concentration for the total $\mathrm{Fe}, \mathrm{SiO}_{2}$ and $\mathrm{Al}_{2} \mathrm{O}_{3}$, while the curves are linear only in the range of more than $0.2 \%$ and $0.8 \%$ for $\mathrm{CaO}$ and $\mathrm{MgO}$ respectively. Accordingly, the "graphite grinding method" may be unsuitable for the analyses of $\mathrm{CaO}$ of less than $0.2 \%$ and $\mathrm{MgO}$ of less than $0.8 \%$.

Furthermore, with regard to the repeatabilities, the "graphite grinding method" was compared with the

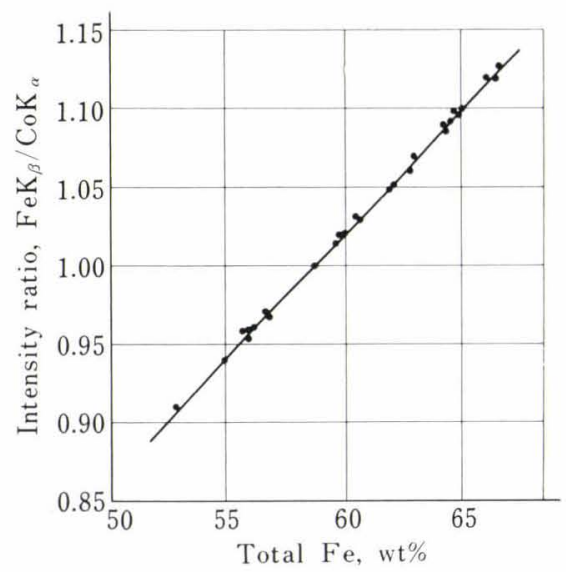

Fig. 2. Calibration curve for Total Fe

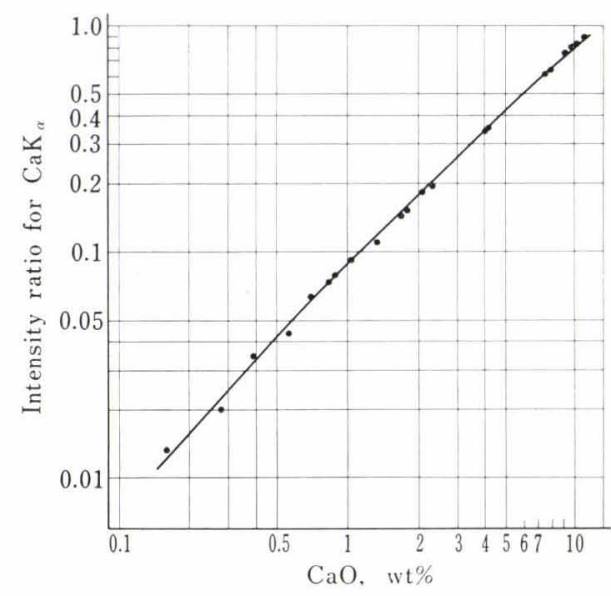

Fig. 3. Calibration curve for $\mathrm{CaO}$
"PSM grinding method" now used preferably. Table 4 shows the results obtained in the investigation. It was found that the "graphite grinding method" was superior to the "PSM grinding method" with regard to the coefficients of variation.

And then, precision $\left(\sigma_{d}\right)$, that is, the standard deviation of the difference between the analytical values and standard chemical values

$$
\sigma_{d}=\sqrt{\frac{\sum(X-C)^{2}}{n-1}}
$$

was examined in the case of the "graphite grinding method", where $X$ was the analytical value by an X-ray fluorescence technique, $C$ was the standard

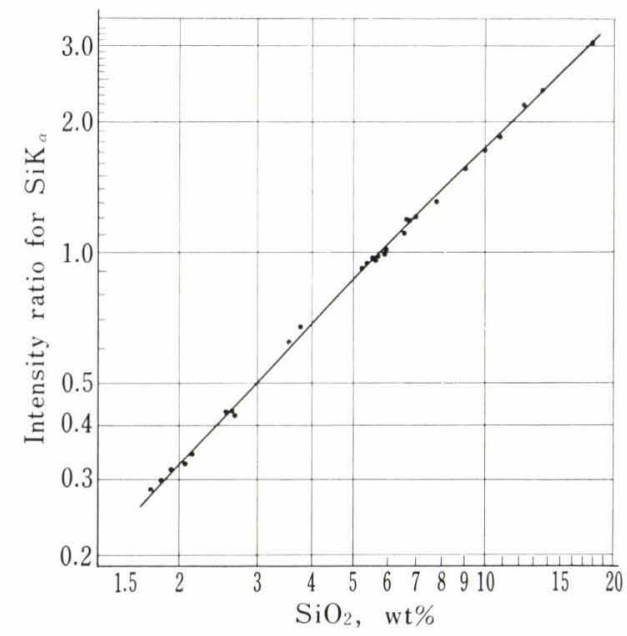

Fig. 4. Calibration curve for $\mathrm{SiO}_{2}$

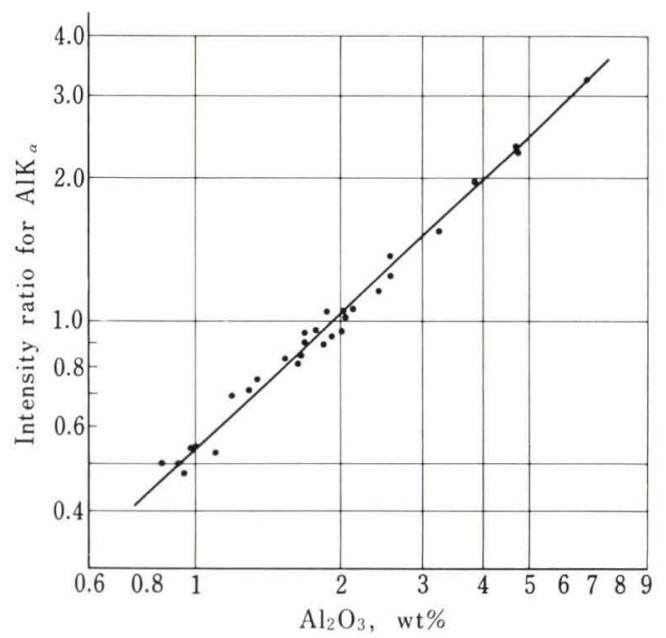

Fig. 5. Calibration curve for $\mathrm{Al}_{2} \mathrm{O}_{3}$

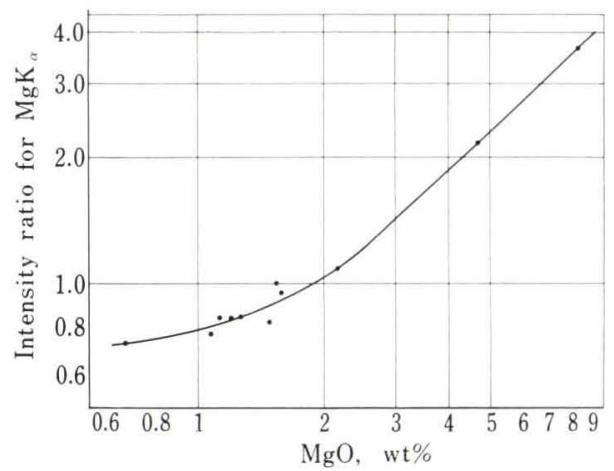

Fig. 6. Calibration curve for $\mathrm{MgO}$ 
Table 4. Repeatability of Fe for PSM-wet grinding method and graphite-dry grinding method $(n=5)$

\begin{tabular}{c|l|c|c|c}
\hline Ore & Grinding method & $\begin{array}{c}\text { Mean } \\
\text { value* }\end{array}$ & $\sigma$ & $\begin{array}{c}\text { Coefficients of } \\
\text { variation (\%) }\end{array}$ \\
\hline \multirow{2}{*}{ Goa } & PSM method & 0.760 & 0.0083 & 1.09 \\
& Graphite method & 0.758 & 0.0055 & 0.72 \\
\hline \multirow{2}{*}{ Brazil } & PSM method & 0.947 & 0.0077 & 0.81 \\
& Graphite method & 0.937 & 0.0047 & 0.50 \\
\hline
\end{tabular}

* Analytical values are shown with X-ray intensity ratio of $\operatorname{FeK} \beta$ for $\operatorname{CoK} \alpha$.

Table 5. Precision $\left(\sigma_{d}\right)^{*}$ in dry grinding method using graphite as a binder

\begin{tabular}{c|c} 
Component & $\sigma_{d}$ \\
\hline $\mathrm{T} . \mathrm{Fe}$ & 0.43 \\
$\mathrm{CaO}$ & 0.05 \\
\hline $\mathrm{SiO}_{2}$ & 0.32 \\
\hline $\mathrm{Al}_{2} \mathrm{O}_{3}$ & 0.25 \\
\hline $\mathrm{MgO}$ & 0.35
\end{tabular}

* Reference values cooperated in Nippon Steel, with wet grinding method using styrene-maleic acid copolymer as a binder : T. Fe (0.4), $\mathrm{CaO}$ (0.09), $\mathrm{SiO}_{2}(0.4), \mathrm{Al}_{2} \mathrm{O}_{3}$ (0.3), and $\mathrm{MgO}$ (0.14).

value by a chemical analysis and $n$ was the number of samples authorized. The results obtained are summarized in Table 5. It may be concluded that the values are reasonably excellent as the values in an $\mathrm{X}$ ray fluorescence analysis. As one of the references, the following values of $\sigma_{d}$ had been obtained for other iron ores through the "PSM grinding method" in our corporation; 0.4 for total Fe, 0.09 for $\mathrm{CaO}$, 0.4 for $\mathrm{SiO}_{2}, 0.3$ for $\mathrm{Al}_{2} \mathrm{O}_{3}$ and 0.14 for $\mathrm{MgO}$. It may be also concluded from the results that the "graphite grinding method " was an excellent sample preparing technique. However, these brands and the number of samples are not same, so both date cannot be compared.

\section{Discussion}

It is well known that the effect of particle size of samples is remarkable in an X-ray fluorescence analysis and it is then said that the particle cannot be theoretically regarded as any homogeneity in X-ray analysis, if the size is not arranged to less than 2 to $3 \mu \mathrm{m} .^{4)}$ The effect of particle size was mainly discussed below, on the basis of the results obtained in this investigation. Especially in this investigation, it was examined whether the graphite powder could be used or not as a grinding agent and binder, from the view point that the powder had been widely employed as a solid lubricant in order to obtain minute iron ores. As the results, it was proved that the briquet became intimately homogeneous as the particle size of iron ores could be easily ground to less than $1 \mu \mathrm{m}$ and the internal standard material was uni-

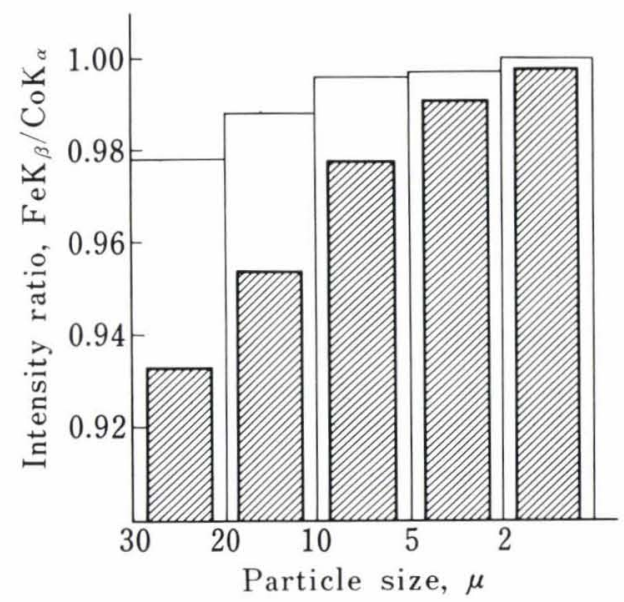

Pressure : $2 \mathrm{t} / \mathrm{cm}^{2}$

Fig. 7. Variation of $\mathrm{X}$-ray intensities with particle size of iron ores

formly mixed with the iron ores by the "graphite grinding method".

Further, the variation of fluorescent X-ray intensities were examined in the minute ranges of less than $20 \mu \mathrm{m}$ which had not been discussed untill then, in order to confirm experimentally the above phenomena. The results obtained are well shown in Fig. 7. In the case of the pressure of $2 \mathrm{t} / \mathrm{cm}^{2}$, the effect of particle size is remarkable and the fluourescent X-ray intensity falls down as the particle size becomes larger. The effect is, however, relieved in the pressure of $12 \mathrm{t} / \mathrm{cm}^{2}$. Accordingly, in order to obtain a stable fluorescent $\mathrm{X}$-ray intensity, it is important that the diameters of particles are made as small as possible and are arranged uniformly. Moreover, it is possible that relatively stable intensity for fluorescent X-ray can be obtained in the pressure as high as possible, even if the distribution of particle size is in the wide rage like the briquet prepared by the " no binder grinding method". As the above fact, it is of interest that the pressure may be scarcely effective in the range of the particle size of less than $2 \mu \mathrm{m}$. Consequently, it is thought that more useful analysis can be further carried out by utilizing such the information.

Next the correlation was examined between the fluorescent X-ray intensity and the pressure for the preparation of briquet. The effect of pressure on fluorescent X-ray intensity is already known up to this time. As the examination had never been tried for the particle size of less than $2 \mu \mathrm{m}$, however, the effect was investigated for the briquet prepared by the Sweden iron ore of the particle size of less than $2 \mu \mathrm{m}$. Fig. 8 shows the result that the fluorescent X-ray intensities are scarcely different in spite of the voltage of X-ray tube in the range of the pressure of 1 to $12 \mathrm{t} / \mathrm{cm}^{2}$.

From the discussion mentioned above, it was understood that it was important to grind minutely the iron ore and to use the pressure for briquetting as high as possible in the X-ray fluorescence analysis of iron ore through a briquet technique. From these viewpoints, it may be concluded that the rapid treatment of the 


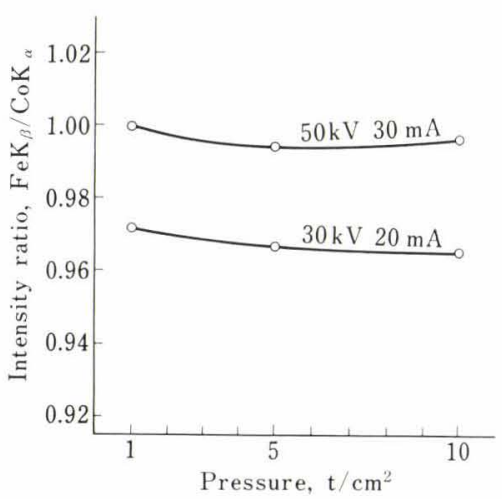

Fig. 8. Variation of $\mathrm{X}$-ray intensities with briquetting pressures

whole analysis and the improvement of repeatability and precision, the purposes of this investigation, can be achieved according to the dry grinding method using graphite powder as an inert binder, which is an effective technique to obtain minute iron ores by grinding. Even in the wet grinding methods, the grinding effects are excellent and the particle sizes obtained are unified within $5 \mu \mathrm{m}$ involving mainly 2 to $3 \mu \mathrm{m}$. However the significant time is necessary to remove an organic solvent and the internal standard material premixed uniformly with iron ore may segregate again in the process of removing the organic solvent. On the other hand, the "graphite grinding method" has the excellent advantages that the iron ores scarcely adhere to the inner wall of grinding vessel and can be easily treated in the whole progress.

As consulting on the graphite powder from the effect of binder, the briquet prepared through the "graphite grinding method" is not necessarily rigid, so the ring of aluminium must be often used to reinforce the briquet.

From the different viewpoint, we will consider the effects of grinding and binder as a nature of material. In the grinding of power, it is thought that an elasticity effect, the nature as flipping powder, is necessary as a grinding agent and a moderate viscosity is also necessary as a binder. Accordingly, the characteristics of the so-called "viscoelasticity" commonly used in the field of polymer chemistry is estimated to hold also for the nature of assistant agent in briquetting. If the concept can be considered with the nature of powder, it is hoped that the investigation will be promoted as a clue to refer a grinding agent and binder, but the viscoelasticity of solid had not been measured so far.

\section{Conclusion}

In order to carry out rapidly and to improve the repeatability in the $\mathrm{X}$-ray fluorescence analysis of iron ores through a briquet technique, a new grinding method was developed by using graphite as an inert binder and the surface characteristics of briquet prepared through the four different grinding methods involving the "graphite grinding method" were investigated by the use of an electron probe microanalyzer, a scanning electron microscope and so on. The results obtained are summarized as follows:

(1) The "graphite grinding method" is suitable to obtain minute iron ores and to grind them easily to the particle size of less than $1 \mu \mathrm{m}$, in comparison with the three grinding methods which have been used as sampling techniques so far.

(2) The "graphite grinding method" can be easily treated and the ground powder obtained can be immediately pressed without further operation, since the powders do not adhere to the inner wall of grinding vessel. Accordingly, the considerable time can be shortened for the preparation of briquet.

(3) The internal standard material $\left(\mathrm{Co}_{2} \mathrm{O}_{3}\right)$ is uniformly dispersed in the briquet prepared by the "graphite grinding method" in comparison with the other three grinding methods.

(4) By adopting the "graphite grinding method", the calibration curves can be adequately collected to one line for the main components, total Fe, $\mathrm{CaO}$, $\mathrm{SiO}_{2}, \mathrm{Al}_{2} \mathrm{O}_{3}$ and $\mathrm{MgO}$, in iron ores.

(5) Repeatability and precision $\left(\sigma_{\mathrm{d}}\right)$ was improved by the use of the " graphite grinding method".

As mentioned above, the "graphite grinding method " is an excellent briquetting procedure in the $\mathrm{X}$-ray fluorescence analysis of iron ores, since graphite powder plays a role as a lubricant agent in the preparation of homogeneous briquet. The "graphite grinding method " is also useful as a sample preparation procedure in the analysis for process control.

\section{Acknowledgements}

The authors would like to thank Dr. T. Otake, the managing director of the Nippon Steel Corporation, for the encouragement and support and Dr. K. Segawa and Mr. R. Matsumoto for helpful discussion during the course of this research. Thanks are also given to Mr. S. Funaki and Miss M. Yamazaki of their Laboratories, analysis sections of Products R \& D Laboratories, Nagoya and Kimitsu works of their corporation for their assistance in the experimental work.

\section{REFERENCES}

1) M. Sasaki, Y. Uzuki and H. Kawase: J. Japan Inst. Metals, 34 (1970), 1151

2) T. Adachi: Advances in X-Ray Analysis (Japan), II (1971), 92.

3) A. Reid and E.J. Ronnie: Steel Times, (1970), 344.

4) K. Kawamura, T. Watanabe, K. Nishizaka, M. Onodera and T. Uemura: J. Japan Inst. Metals, 33 (1969), 679.

5) A. D. Ambrose, R. Rutherford and S. Muir: Metallurgia, 82 (1970), 119

6) G. Staats and H. Brück: Z. Anal. Chem., 250 (1970), 289

7) H. Hattori: Bull. Geol. Survey Japan, 22 (1971), 103.

8) R. H. Myers, D. Womeldorph and B. J. Alley: Anal. Chem., 39, (1967), 1031 .

9) A. R. Büchner: Spectrochim. Acta, 23B (1968), 295.

10) F. Claisse: Spectrochim. Acta, 25B (1970), 209.

11) G. Stehno, H. Ebel, A. Wagendristel, and P. Stalicky: Z. Metallk., 61 (1970), 156.

12) R. F. Deacon and J. E. Goodman: Proc. Roy. Soc., 243 (1958), 464.

13) Y. Tsuya: Junkatsu (Lubricant), 16 (1971), 277.

14) "Studies on structure and property of iron ores", unpublished.

15) O. Kammori, I. Taguchi and K. Takimoto: J. Japan Inst. Metals, 33 (1969), 669. 